\title{
Occult Metastatic Papillary Thyroid Carcinoma Presenting as Submandibular Mass: An Unusual Case
}

\author{
Rashu P Mittal ${ }^{1}$, Rajesh R Yadav², Shashikantkant K Mhashal ${ }^{3}$, Payal R Mittal ${ }^{4}$
}

\begin{abstract}
Papillary carcinoma is the most common variant of thyroid cancer. A tumor less than $1 \mathrm{~cm}$ in size is labelled as the papillary thyroid microcarcinoma (PTMC). Such tumors have an excellent prognosis, although a few may metastasize to cervical neck nodes. However, an infiltrated palpable neck node without evidence of thyroid disease is rare. Here, we report a case of an isolated submandibular metastasis from a clinically occult papillary thyroid carcinoma in a 40-year-old woman. The initial surgery was performed on the basis of the fine needle aspiration cytology (FNAC) report of basal cell adenoma vs cellular pleomorphic adenoma. The case was a total histopathological surprise as it was reported as a metastasis from papillary thyroid carcinoma. Subsequently total thyroidectomy and modified neck dissection was performed as per the standard surgical guidelines.
\end{abstract}

Keywords: Occult metastasis, Papillary thyroid microcarcinoma, Submandibular gland, Thyroid gland.

International Journal of Head and Neck Surgery (2018): 10.5005/jp-journals-10001-1360

\section{Case Description}

A 40-year-old woman presented with the right side submandibular swelling for 3 years which was gradually progressive in nature. There were no other troublesome symptoms reported by the patient such as pain or increase in size during the meal. No other significant medical history could be elicited.

Examination revealed a $3 \times 3 \mathrm{~cm}$ size, firm, and nontender swelling in the right submandibular region. A fine needle aspiration cytology (FNAC) study showed features suggestive of basal cell adenoma vs cellular pleomorphic adenoma. The ultrasonography (USG) neck mainly revealed a $3.0 \times 3.5 \times 2.8 \mathrm{~cm}$-sized hypoechoic lesion in the right submandibular region.

A complete submandibular mass excision was carried out on the right side and the specimen was subjected to histopathological examination. To our surprise, the biopsy report came out with a final diagnosis of papillary carcinoma favoring metastatic mass (Fig. 1).

The postoperatively USG neck was carried out which revealed a few tiny nodules in both the thyroid lobes. A USG-guided FNAC of the thyroid gland was ordered which revealed inconclusive report.

The patient subsequently underwent total thyroidectomy with the right-side modified neck dissection (MND) type III (levels I-V) along with a bilateral central compartment clearance. Complete specimen along with neck nodes was sent for histopathological examination which revealed differentiated papillary carcinoma involving the upper pole of the right lobe of thyroid with scanty foci of extrathyroidal extension and nodal metastasis (Fig. 2).

The $100 \mu \mathrm{Ci}$ neck scan was ordered a month later which showed an iodine uptake of $0.92 \%$ with no active foci (probably due to iodine interference). A large dose scan after 3 months followed with 122 $\mu \mathrm{Ci}$ of $\mathrm{I}^{131}$ was given orally. No evidence of any recurrence or nodal presentation is noted in the follow-up period, till date.

\section{Discussion}

A papillary variant is the most common form of thyroid cancer and commonly remains clinically silent until its incidental histological diagnosis in surgical material or at autopsy. Nodal metastases relating to papillary thyroid carcinoma commonly involve the
${ }^{1}$ Department of ENT, Shatabdi Hospital, Mumbai, Maharashtra, India ${ }^{2}$ Department of ENT, Bhagwati Hospital, Mumbai, Maharashtra, India ${ }^{3}$ Department of ENT, RN Cooper Hospital, Mumbai, Maharashtra, India

${ }^{4}$ Department of Oral and Maxillofacial Pathology, Smile a Mile Clinic, Mumbai, Maharashtra, India

Corresponding Author: Rashu P Mittal, Department of ENT, Shatabdi Hospital, Mumbai, Maharashtra, India, Phone: +91 9892996132, e-mail: drmittal.rashu@gmail.com

How to cite this article: Mittal RP, Yadav RR, et al. Occult Metastatic Papillary Thyroid Carcinoma Presenting as Submandibular Mass: An Unusual Case. Int J Head Neck Surg 2018;9(4):131-133.

Source of support: Nil

Conflict of interest: None

central compartment. Submandibular nodal metastases are rare and are usually associated with extensive cervical metastases. ${ }^{1}$

Compared with other cancers, papillary carcinoma of the thyroid gland is a relatively indolent disease with a better survival rate. ${ }^{2}$ Papillary microcarcinoma is a morphological variant of papillary carcinoma, originally described in 1949 by Hazard et al. ${ }^{3}$ based on the size of the lesion. The upper limit of size to define papillary microcarcinoma is generally $10 \mathrm{~mm}$. This case is unusual in the aspect that the metastasis was confined to a single site in the right submandibular space without cervical lymphadenopathy.

Patients with clinical occult thyroid papillary carcinoma may rarely present with metastatic neck nodes. ${ }^{4}$ Distant metastases from an occult papillary thyroid carcinoma are extremely rare. To our knowledge, there have been only a few reports of an isolated metastasis from an occult papillary thyroid carcinoma to the submandibular gland. The rarity of this occurrence can be appraised from the fact that only $1-4 \%$ of all head and neck tumors are malignant neoplasms of the major salivary glands. ${ }^{5}$ Metastatic tumors account for approximately $3 \%$ of malignant salivary gland neoplasms and only $10-20 \%$ of such metastatic tumors occur in the submandibular glands. ${ }^{5}$ 


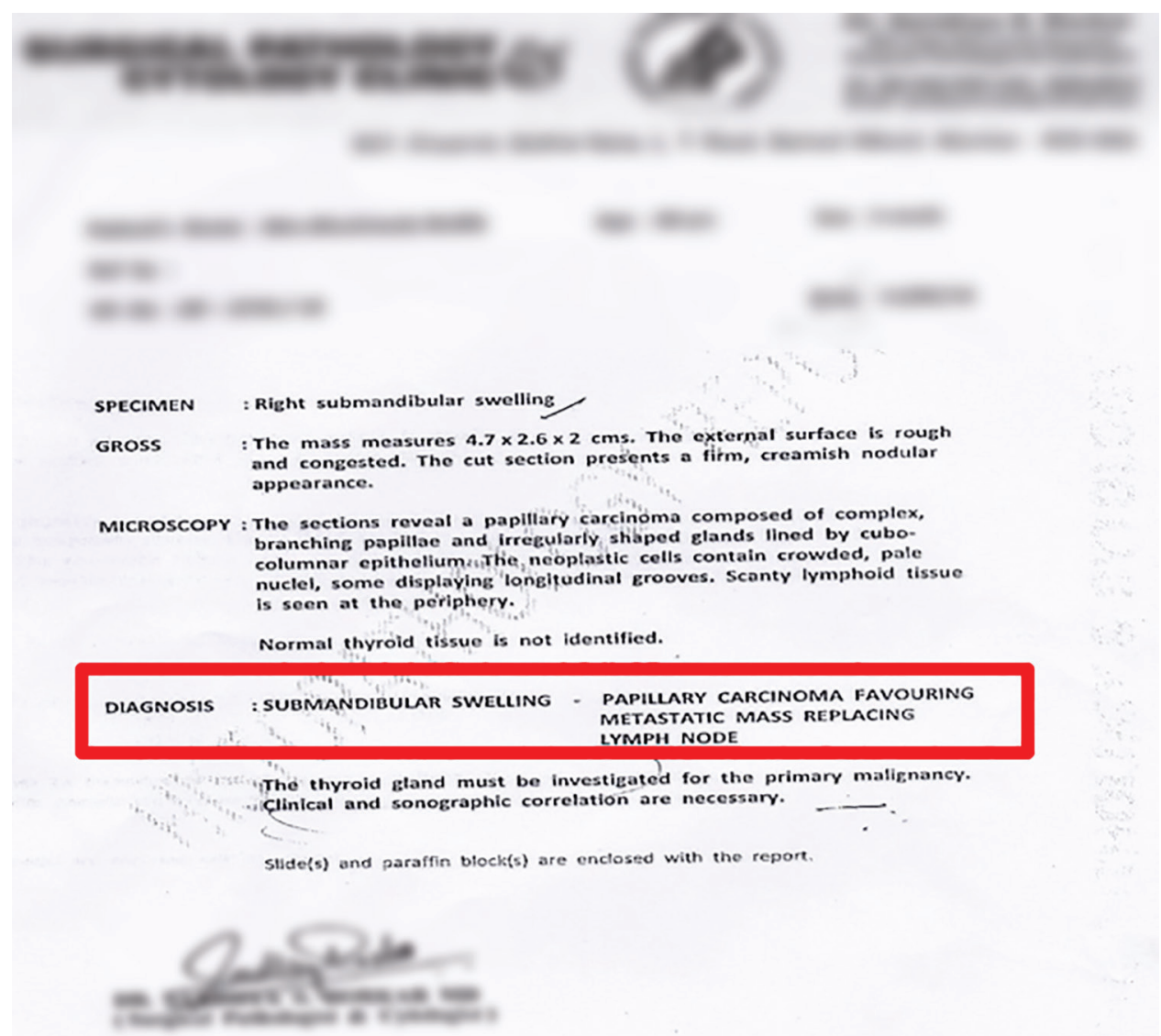

Fig. 1: Histopathology report: excised submandibular mass

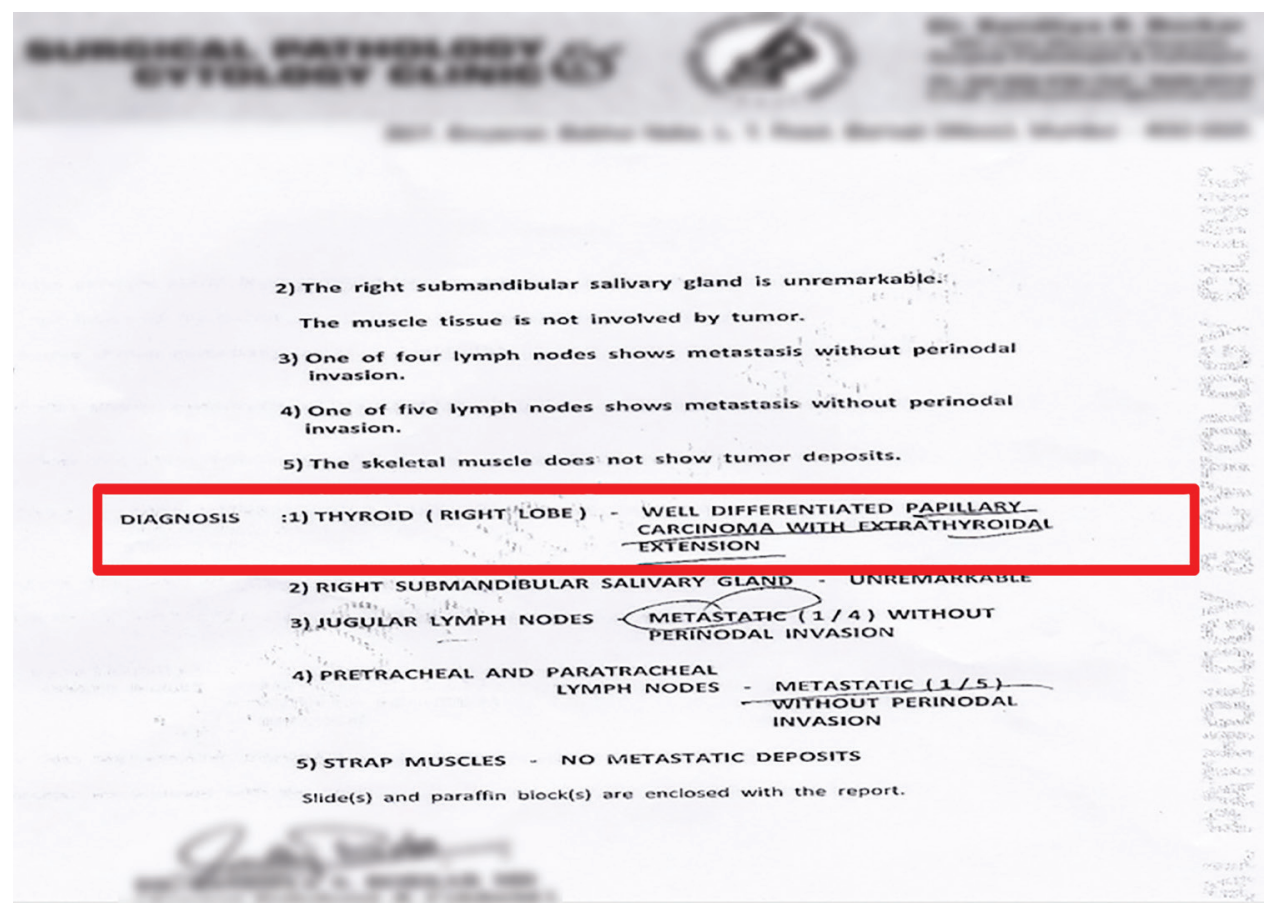

Fig. 2: Histopathology report: excised total thyroidectomy specimen along with neck nodes

Among all the salivary gland tumors, $85 \%$ occurred in the parotid gland of which $18 \%$ were malignant, $7 \%$ were in the submandibular gland of which $37 \%$ were malignant, and $8 \%$ in the major sublingual and the minor salivary glands of which $47 \%$ were malignant. ${ }^{6}$
Whereas metastases spread to the parotid gland is mainly by the lymphatic route, the majority of metastases to the submandibular gland are from a distant source namely the hematogenous route. Possibly, this difference lies in the paucity of the lymphoid tissue 
inside the submandibular gland, while the parotid gland may contain abundant lymphatic tissue within its capsule. ${ }^{7}$ While the extensive lymphatics surrounding the parotid gland make it susceptible to metastases from head and neck tumors, scarcity of the lymphatic tissue surrounding the submandibular gland protects it from such spread. ${ }^{8}$

Fine needle biopsy (FNB) cytology of a cervical lymph node has been proposed as a very useful procedure to discover occult thyroid carcinoma lying within the node. ${ }^{9}$ However, other studies have reported $29-43 \%$ and even $50 \%$ of non-diagnostic or false-negative results in FNB cytology of the affected lymph node. The possibility of false-negative diagnosis is even higher in the case of cystic degeneration of the lymph node metastasis ${ }^{10}$ because the classical pathologic features of PTMC, such as papillae and psammoma bodies, may be sparse or not present, and nuclear abnormalities may be the only finding. ${ }^{11}$ Therefore, negative FNB cytology results cannot safely exclude the thyroid origin of the lesion.

\section{Conclusion}

In conclusion, a patient with PTMC presenting as a metastatic mass with no evidence of primary thyroid tumor in thyroid imaging and inconclusive lymph node FNB cytology is reported. In such cases, thyroid malignancy should be excluded. Lymph node excision and histological examination provide the definite diagnosis.

A palpable lesion in the submandibular gland is a primitive salivary gland tumor; ${ }^{12}$ metastatic tumors are rare. This report wants to emphasize that a metastasis from an occult neoplasm must be considered whenever an unusual carcinoma in seen in a salivary gland, especially the submandibular gland.

\section{References}

1. Noguchi S, Noguchi A, et al. Papillary carcinoma of the thyroid. I. Developing pattern of metastasis. Cancer 1970;26:1053-1060. DOI: 10.1002/1097-0142(197011)26:5<1053::AID-CNCR2820260513>3.0.CO;2-X.
2. Yousem DM, Scheff AM. Thyroid and parathyroid. In. Som PM, Curtin HD. ed. Head and neck imaging, 3rd ed. St Louis: Mosby; 1996. pp. 952-975.

3. Hazard JB, Crile G Jr, et al. Non-encapsulated sclerosing tumors of the thyroid. J Clin Endocrinol 1949;9:1216-1231. DOI: 10.1210/jcem9-11-1216.

4. Allo MD, Christianson W, et al. Not all "occult" papillary carcinomas are "minimal". Surgery 1988;104:971-976.

5. Vaidya AM, Vaidya AM, et al. Isolated submandibular gland metastasis from oral cavity squamous cell carcinoma. Am J Otolaryngol 1999;20:172-175. DOI: 10.1016/S0196-0709(99)90067-4.

6. Eneroth CM. Salivary gland tumors in the parotid gland, submandibular gland, and the palate region. Cancer 1971;27:1415-1418. DOI: 10.1002/1097-0142(197106)27:6<1415::AID-CNCR2820270622> 3.0.CO;2-X.

7. Feinmesser R, Lahovitzki $G$, et al. Metastatic carcinoma to the submandibular salivary gland. J Oral Maxillofac Surg 1982;40: 592-610. DOI: 10.1016/0278-2391(82)90290-7.

8. Cain AJ, Goodland J, et al. Metachronous bilateral submandibular gland metastases from carcinoma of the breast. J Laryngol Otol 2001;115:683-684. DOI: 10.1258/0022215011908649.

9. Matsuda M, Nagumo S, et al. Occult thyroid cancer discovered by fine-needle aspiration cytology of cervical lymph node: a report of three cases. Diagn Cytopathol 1991;7:299-303. DOI: 10.1002/ dc. 2840070318 .

10. Cunha N, Rodrigues F, et al. Thyroglobulin detection in fine-needle aspirates of cervical lymph nodes: a technique for the diagnosis of metastatic differentiated thyroid cancer. Eur J Endocrinol 2007;157:101-107. DOI: 10.1530/EJE-07-0088.

11. Monchik JM, De Petris G, et al. Occult papillary carcinoma of the thyroid presenting as a cervical cyst. Surgery 2001;129:429-432. DOI: 10.1016/S0039-6060(01)60495-1.

12. Eneroth CM. Salivary gland tumors in the parotid gland, submandibular gland, and the palate region. Cancer 1971;27:1415-1418. DOI: 10.1002/1097-0142(197106)27:6<1415::AID-CNCR2820270622> 3.0.CO;2-X. 